\title{
Conversando: Entre Duas Fileiras. Entrevista com Gerald Thomas
}

\section{Talking: Between Two Lines. Interview with Gerald Thomas}

Entrevista com Gerald Thomas concedida a

Gunter Axt ${ }^{1}$ 


\section{Resumo}

Nessa entrevista, concedida ao historiador Gunter Axt, Gerald Thomas responde a perguntas sobre seu último livro, o autobiográfico, Entre duas fileiras, lançado em 2016, e temas nele tratados.

Palavras-chave: Gerald Thomas; autobiografia; Entre duas fileiras; teatro

\section{Abstract}

In this interview, given to historian Gunter Axt, Gerald Thomas answers questions about his latest book, the autobiographical Between Two Lines, released in 2016, and topics covered in it.

Keywords: Gerald Thomas; autobiography; Between Two Lines; theatre 


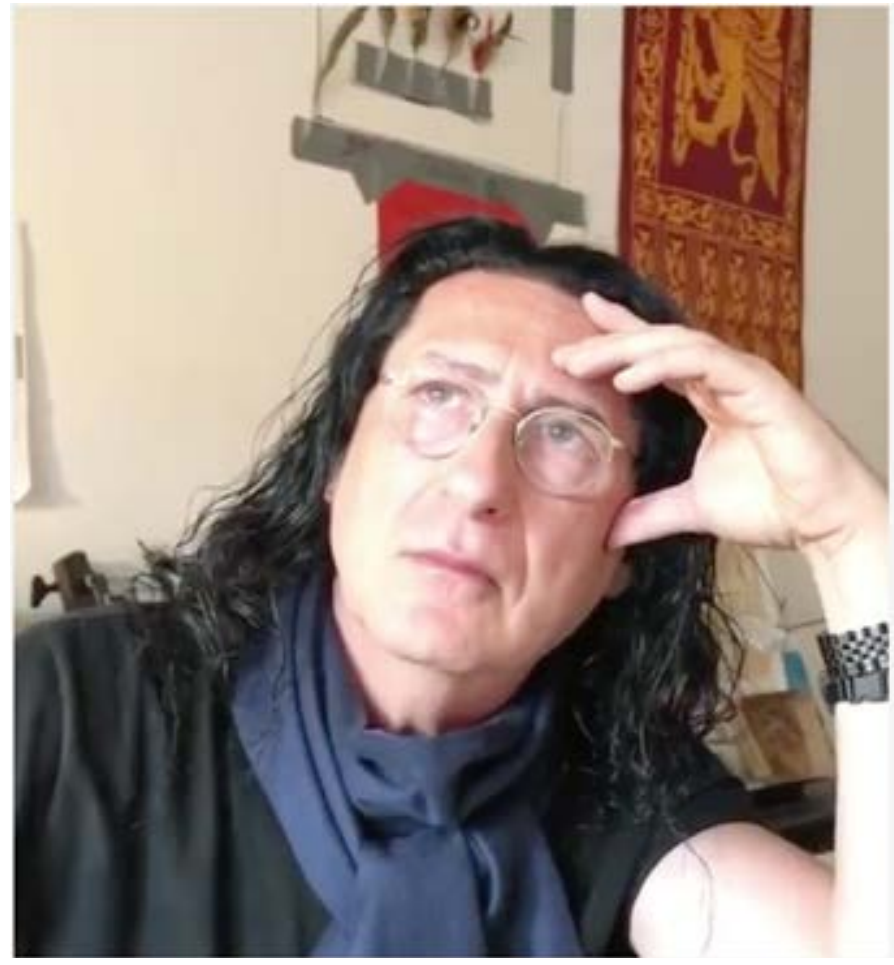

Gerald Thomas - selfie - Acervo: Gunter Axt

Gerald Thomas Sievers nasceu em Nova York, em 1ㅇde julho de 1954. De família judaica, perdeu familiares nos campos de concentração de Auschwitz e Buchenwald. Filho de pai alemão e mãe galesa, morou até os 7 anos nos Estados Unidos. Migrou com a família para o Rio de Janeiro, onde começou seus estudos de artes com Ivan Serpa e Hélio Oiticica. Em São Paulo iniciou-se no teatro com Ruth Escobar. Aos 14 anos, transferiu-se para Nova York, onde residiu com o artista plástico Hélio Oiticica. Aos 16 anos, mudou-se para Londres e casou-se pela primeira vez. Recebeu grau em Filosofia da London Education Authority. Retornando a Nova York, iniciou sua carreira de diretor, produzindo e dirigindo peças dramáticas com textos baseados nos escritos do irlandês Samuel Beckett, no espaço experimental La MaMa. Em 1985, já no Rio de Janeiro, dirigiu a peça Quatro Vezes Beckett, uma coprodução com o La MaMa. A peça excursionou na Bienal de Viena com Sérgio Brito, Rubens Corrêa, Ítalo Rossi e Richard Riguetti no elenco. Por seu trabalho, Thomas recebeu o Prêmio Molière Especial. Em 1986, dirigiu Quartett, do alemão Heiner Müller, com Tônia Carreiro e Sérgio Brito. Nesse mesmo ano, fundou a "Companhia Ópera Seca", em São Paulo, quando escreveu, dirigiu e apresentou grandes sucessos, entre eles, Eletra Com Creta (1986), A Trilogia Kafka (1988), que lhe concedeu o Prêmio Molière, Carmem Com Filtro (1989), Mattogrosso (1989), Fim de Jogo (1990), M.O.R.T.E. (1990), The Flash and Crash Days (1991), O Império das Meias Verdades (1993) e UnGlauber (1994), os três últimos estrelados por Fernanda Torres. Trabalhou em diferentes parcerias com grandes nomes das artes, como Samuel Beckett, Phillip Glass, Julian Beck e Ellen Stewart. Em 1999, Ventriloquist tornou-se um fenômeno de público e de mídia no Brasil. Nos anos seguintes, montou Nietzche contra Wagner, com música de Borut Krzisnik; Esperando Beckett, com Marília Gabriela; O príncipe de Copacabana, com Reynaldo Giannechini; Deus Ex Machina; Solos Secos; Anchorpectoris, dentre outros espetáculos. Em 2005, escreveu e montou Um Circo de Rins e Fígados, comédia protagonizada por Marco Nanini, que alcançou grande sucesso e itinerou por diversos teatros brasileiros. 
Ao longo de sua carreira colecionou sucessos, fracassos e polêmicas. Em 1995, duelou pela imprensa italiana e brasileira com o compositor Luciano Berio, a propósito do fracasso da montagem de Zaide, em Florença. Em 2003, na apresentação de Tristão e Isolda, de Richard Wagner, no Teatro Municipal do Rio de Janeiro, diante das vaias do público, baixou as calças e mostrou as nádegas, o que the valeu um processo por ato obsceno, que acabou julgado em grau de recurso no Supremo Tribunal Federal, onde foi absolvido.

Desencantando com o teatro, em 2009, chegou a lançar um manifesto anunciando seu afastamento dos palcos. Mas no ano seguinte, em Londres, fundou a Cia London Dry Opera. Escreveu e dirigiu Throats. Retornou aos palcos em 2014, quando estreou no Brasil Entredentes, em parceria com Ney Latorraca. Em 2017, montou em São Paulo o aclamado Dilúvio. Gerald já se apresentou em muitos teatros, como o Lincoln Center em Nova York, o Teatro Estatal de Munique, o Wiener Festwochen de Viena, tendo se envolvido em montagens nos Estados Unidos, no Brasil, na Inglaterra, na Alemanha, Dinamarca, Polônia e Itália.

Gerald Thomas casou-se quatro vezes: Com a bailarina Jill Francis Drower, com a cineasta Daniela Thomas, com a atriz Fernanda Torres e com a preparadora de atores Daniela Visco. Teve inúmeros relacionamentos, como com as atrizes Bete Coelho, Giulia Gam, Camila Morgado e Fabiana Guglielmetti. Além do teatro, Gerald foi cartunista do New York Times, manteve colunas em importantes jornais brasileiros, e possui desde 2000 um blog. Recebeu três Prêmios Molière e outros 18 prêmios e foi tema de documentários de televisão para a rede alemã NDR 3, a rede brasileira TV Cultura, a rede pública PBS dos EUA e a TV austríaca ORF. Existem três livros sobre o trabalho de Thomas. Dois deles em português e um em inglês: $O$ Encenador de Si Mesmo (editora Perspectiva), Memória e Invenção: Gerald Thomas em Cena, de Silvia Fernandes (editora Perspectiva) e Flash and Crash Days, de David George (Garand Publishing Inc).

$\mathrm{Na}$ autobiografia Entre duas fileiras, lançada em 2016 pela Record, o artista complexo, torturado e homem do mundo, reconta sua trajetória de modo caleidoscópico e pictórico, numa narrativa não linear, que vai e vem, da tentativa de suicídio nos Alpes suiços, em 2015, aos bastidores das relações e colaborações com alguns dos grandes nomes das artes, como Hélio Oiticica, Samuel Beckett e Ellen Stewart. 


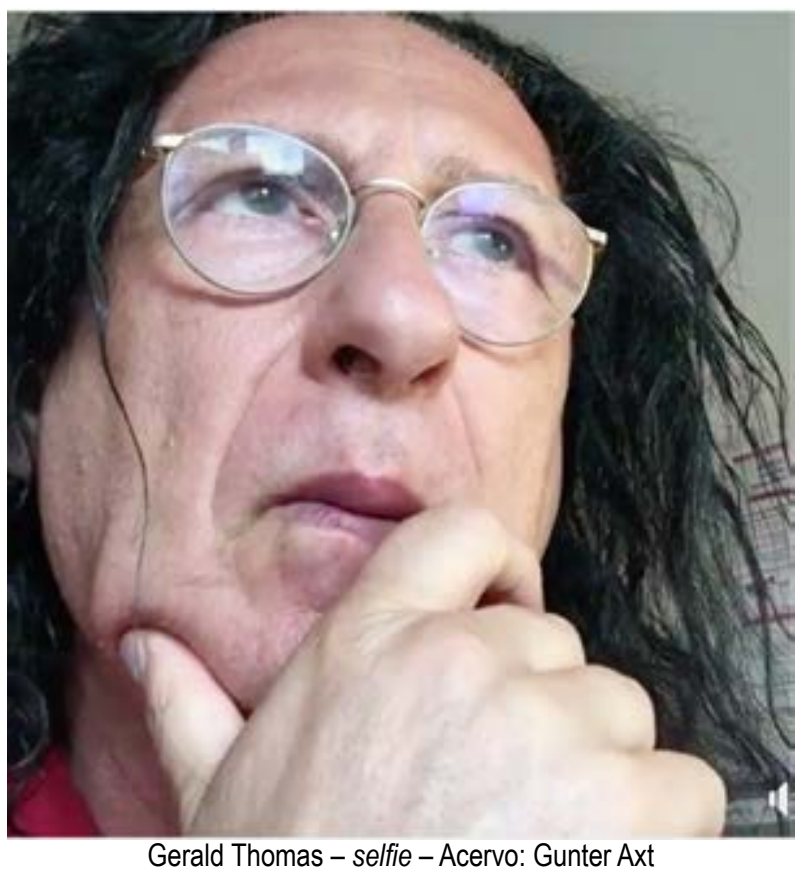

Como você escreveu Entre Duas Fileiras? É uma coleção de textos produzidos em momentos diferentes da sua vida, ou você dedicou um tempo para se concentrar na concepção e na redação da obra, do início ao fim?

Através de 11 anos. Teve vários nomes (And Dead, We Walk, Truths And Lies) etc. Escrevo em inglês. Comecei em 2004 lá em Wengen, Alpes Suíços. Eu separava 3 horas por dia - mesmo que eu estivesse no meio de uma produção na Ásia - para escrever. Concepção, não. Isso só veio com os milhões de volumes todos prontos. Muita gente leu, muita gente opinou, muitas opiniões foram válidas.

Como foi o processo de selecionar o que deveria entrar no livro e o que não seria abordado? Você, por exemplo, oferece detalhes de relações pessoais com amigos e companheiros como Hélio Oiticica e Ellen Stewart, já falecidos, mas é econômico ao comentar seus relacionamentos mais recentes, como os com Daniela, Bete Coelho, Giulia Gam e Fernanda Torres, dentre outros. Você oferece um quadro interessante do contexto de produção de montagens mais antigas, como a Trilogia Beckett e The Flash and the Crash Days (com destaque pitoresco para o azedume de Ellen Stewart para com a famosa cena da masturbação entre mãe e filha), mas há pouco sobre montagens mais recentes, como Um Circo de Rins e Fígados ou Entredentes. Você esmiúça o conflito havido com o compositor Luciano Berio, mas deixa de abordar vários outros, alguns dos quais também chegaram à imprensa.

Os mortos não incomodam e não entram com processo. Os vivos são foda. Muita coisa (a respeito dos vivos) foi consensualmente retirada pelo editor e por mim, depois de alguma revisão. Talvez eu seja - de fato - mais encantado mesmo com o passado mais remoto. O passado recente é mais burocrático e a história recente é mais boring, mais habitual. Quando se volta lá para atrás, as coisas são realmente românticas, o gosto do café é realmente fantástico, o look dos automóveis ainda é aquele mais arredondado e o cheiro das coisas ainda tem um leve perfume de Gitanes. Depois de 11 de setembro, para mim, tudo cheira a amianto e é grotescamente chato. 
Esse não é seu primeiro livro, ou o primeiro livro sobre você: o que essa obra tem de específico em relação às outras?

Eu gosto muito do Encenador de Si Mesmo. Talvez por ser o primeiro. Talvez pelo fato de eu me reconhecer mais ousado lá e menos compromissado com a minha própria imagem. Nesse, agora, eu já acredito um pouco no Gerald como um half-cult. $\mathrm{E}$ isso é ridículo. Mas eu acabei comprando o que dizem (alguns dizem) a meu respeito.

Você relata em seu livro o encontro com Victor Garcia e a experiência de acompanhar os ensaios de $\mathbf{O}$ Balcão. Como isso influenciou a sua trajetória?

Calma. Como? Como isso influenciou a minha trajetória? TOTALMENTE - influenciou tudo! O Victor era um desses gênios totais que entendiam TUDO sobre tudo e não ligava para o palco. Ele encenava o "em torno", entende? Criava "climas", criava confusões que "resultavam" numa espécie de bordel da Irma, o bordel da hipocrisia do Balcão de Genet. Isso SIM é um DIRETOR de teatro. Poucos na história são assim!

\section{Alguma coisa do método de direção de Garcia passou para você?}

...não. Acho que acabei não absorvendo esse estilo não. Assim como não absorvi Peter Brook, apesar de ter mergulhado nele logo após o Victor. Foi em Londres, meses depois.

Você menciona no livro "medos" do elenco (cantores, atores) para com as "ideias loucas do diretor". E "medos" do compositor ao compor uma grande peça, ou do diretor ao dirigi-la. Como administrar tudo isso sem exacerbar conflitos e buscando um resultado eficaz ao final?

Eu juro que não sei. Cada fragmento no seu lugar. Quando olho para trás, me lembro de cada coisa!!! Existem tumultos inacreditáveis em torno de NADA. Assim como assisti o grupo do Kantor TREMER de medo por ainda estar na rua às 11 da noite aqui em NYC. Tinham que estar nos quartos as $22 \mathrm{hs} 30 \mathrm{~min}$ (ordem da KGB época da União Soviética, início dos anos 1980). No meu caso, eu vi todo mundo tremer por todos os motivos. Alguns monárquicos, alguns semi-monárquicos, alguns quase plebeios, alguns quase fascistas e outros heréticos, outros helênicos e outros helvéticos. Mas TODOS por questões hierárquicas. Quase daquela maneira que você testemunhou em POA entre Arrabal e eu². Teve um motivo? Não. Not really.

Você dirigiu e montou peças e óperas em várias cidades, países e teatros diferentes. $O$ que há de similar e diferente em dirigir atores no Rio de Janeiro, em São Paulo, em Nova lorque, em Londres, em Frankfurt...?

As colunas barrocas e rococós do Cuvillies Theater em Munique (Teatro estatal) são lindas. Mas o fato é que existe uma tremenda ORGanização no 10 mundo que nos permite fazer o que quisermos. Ao mesmo tempo, existe uma VONTADE, UMA FOME LINDA DE BOLA no Brasil, por falta de tudo, que dá inveja. Dá mais ainda vontade de fazer as coisas. Mas a diferença está na tecnologia. Claro.

2 Gerald Thomas faz referência a uma discussão havida em 12 de maio de 2008, num jantar no restaurante La Piedra Chaparro, em Porto Alegre, com o dramaturgo espanhol Fernando Arrabal, que acabou repercutindo na imprensa. 
Seus atores no palco frequentemente parecem extravasar emoções de modo arrebatador. Como você faz para trazer essa pungência à tona? É intuitivo? Há uma técnica?

Essa "Técnica" se chama: "OPERA SECA". É opera sem ser cantada. É seca! Tem uma música e os atores tem uma partitura a seguir. Mas não são cantores. Esse termo quem deu foi a Ellen Stewart. Ela me disse: "honey, what you do is Dry Opera".

Como espectador, sinto como se houvesse algo específico no jeito que você dirige seus atores, no jeito como você faz com que as emoções deles aflorem no palco, um pouco, por exemplo, como Werner Herzog...

Como Bela Lugosi. Como Moisi. Como qualquer um vindo de Toller e Kaiser. Ora, trata-se de Expressionismo Alemão.

As condições de produção mudam muito de um lugar para o outro, ou de um grande teatro para o outro, ou entre teatros de circuito alternativo e teatros tradicionalizados?

RADICALMENTE. Experimente trabalhar em Pontedera, Itália, por exemplo. No ex-centro do Grotowski. Se você consegue um palito, é motivo para se ajoelhar e rezar pra Deus.

E quanto ao público de teatro? É mais ou menos similar nos Estados Unidos, no Brasil, na Ásia e na Europa? Muda muito de um país ou de uma cidade para outra?

Não preciso responder, né? Você sabe que é diferente.

[Risos]. Você diz que olha para uma palavra e pensa em como pode "quebra-la". Gosto da imagem, que me parece quase oposta à de "palavras acolheradas" (algo como um meticuloso processo de adjetivação). Enfim, como essa quebra de palavras impacta a sua arte, especialmente na escrita e na direção?

Acho que devo ao Peter Iden, crítico teatral do Frankfurter Rundschau, o que agora chamo de teatro metalinguístico. Ele intitulou uma crítica à Trilogia Beckett (estrelada por Julian Beck) "Wie Wirklich ist die Wirklichkeit?"3, fazendo referência a um ator moribundo no papel de um personagem moribundo. Olho para uma palavra e sempre penso em como posso quebra-la. Ouço uma voz. Essa voz é linguagem. Eu falo o que a voz me diz para falar. Etimologia trata de como palavras latinas chegaram ao saxão, de como as anglo-saxônicas chegaram ao celta, de como o gaélico implicou, em tantas outras coisas, o modo como o ato da GUERRA seria determinado. Determinado? DETER-MINADO. Determinar é deteriorar e quebrar em passos, em objetivos, em significados, de modo que ao se deteriorar, se torna menos determinada. Assim, uma determinação NÃO é um ato, mas afirmação de um desejo. E, CONTUDO,.... Não levo linguagem tão a sério... Penso metaforicamente, não de forma prática. Estou preso num ciclo joyciano. Tudo está relacionado à Finnegan's Wake.

3 "Quão verdadeira é a verdade? " 
MatoGrosso em 1989: o crítico do New York Times, Frank Rich, disse algo como não ter coragem de escrever sobre a peça antes de consultar o seu psicanalista. Ele te chamou de louco ou de genial? Ou ambos? Há muito de psicanálise em suas peças? Alguma proposta tácita de psicanalise coletiva, com elenco e com plateia?

Disse que eu fazia o meu público - ou melhor, que eu USAVA o meu público pra derramar os meus problemas psicanalíticos nele. Mas disse que gostou da obra. Sempre gosta, mas sim, me achava um doido.

Aliás, como foi a parceria entre você e Phillip Glass na montagem do MatoGrosso? No livro você conta como a ideia surgiu e que Phillip acompanhava os ensaios. Quando eu conheci vocês dois, mais ou menos na mesma época, havia um ruído residual em torno dos resultados da montagem (foi o tambor?) e vocês estavam se falando pouco. Mas isso mudou depois, com Phillip inclusive gravando um belo depoimento sobre você em 2009.

Falando pouco? MattoGrosso foi em 1989. Muita coisa aconteceu. Ele fez muita música para mim. Trilogia Kafka por exemplo. Sim, ele fez esse vídeo aqui: https:// vimeo.com/105034878 mais completo que aquele depoimento que você conhece. Hoje em dia, raramente nos falamos.

Enquanto manteve um apartamento em Ipanema, Phillip escreveu uma peça em tributo à Rocinha (Days and Nights in Rocinha), cuja première foi em 2005, em Erfurt, e que jamais foi executada no Brasil. Você chegou alguma vez a pensar em montar uma peça com essa composição?

Não. Nunca pensei.

Você frequenta ou frequentou o projeto Watermill em Long Island, no qual Phillip Glass de vez em quando aparece? Você e Bob Wilson já chegaram a desenvolver ou a pensar em desenvolver algo junto?

Nunca fui em Watermill. Nunca desenvolvi nada com o Bob. Não faria sentido já que somos, os dois, da mesma profissão. O palco é um só. Dois diretores? Onde já se viu dois goleiros para um mesmo time? (rs)

Como foi a experiência de trabalhar com Heiner Müller? Como foi montar Quartett? Você acha que é uma boa peça?

Odiei todas as vezes. Odiei conviver com ele. Juro que me pergunto até hoje porque eu fiz a première americana dessa peça e a première brasileira também. ODEIO Quartett.

Julian Beck, junto com Judith Malina, foram presos no início dos anos 1970 no Brasil, acusados de porte de drogas, que eles negaram. Alguns anos mais tarde, Julian recomendou que você fosse ao Brasil montar uma peça e se tornar grande. O que exatamente Julian viu no Brasil para the dar tal conselho e superar o constrangimento com a prisão?

O Julian é para mim, um EXEMPLO de vida, um profeta. Ele enxergou o meu futuro no Brasil. Ele sabia que os atores aqui chegavam cansados, exaustos de outros 
trabalhos. Disse: "vá ao Brasil, construa um nome para você, use o dinheiro bem e volte para cá. Eles te darão a capa do New York Times". E assim foi. Em outubro de 1988, me deram a capa do NY Times na ocasião da estreia da Kafka Trilogy.

Você montou peças em vários países e se apresentou em muitos outros. A relação com a crítica muda de um lugar para o outro? Em Nova lorque, por exemplo, há uma crítica especializada off-off-Broadway: ela repercute além desse nicho? Isso influencia o seu trabalho?

Tudo isso mudou imensamente de tempos para cá. Antigamente tínhamos os grandes jornais. Hoje são não sei quantos sites. São sites e mais sites. E blogs e online isso e aquilo. E festa e mais festa e um oba-oba insuportável. Até tenho uma certa saudade daquela critica azeda e severa de antigamente ( $r s)$, tamanho o oba-oba de hoje.

Fato é que sim, o NYTimes tinha críticos para Broadway, Off-Broadway e Off-Off e até Performance ou Installation Theater e por aí vai. Ou seja, se dialogava mesmo com um Mel Gussow ou um Stephen Holden ou Alisa Solomon ou Erica Munk (esses últimos dois do Village Voice, que não existe mais). Mas era VIVA a coisa. Era ALIVE aqui no Village, onde o La MaMa reinava e o Public Theater era o segundo mas...a cena era VIVA e borbulhava e... pegava fogo e uma estreia causava incêndios, entende? Era FANTASTICO o que uma première causava!! Ou mesmo no BAM em Brooklyn!!! Se era o Philip (Glass) com algo novo, ou o Bob (Wilson) ou nós do La MaMa trazendo o Kazuo Ohno ou o Kantor ou a Pina Bausch trazendo algo novo... ou mesmo o Joe Chaikin ou sei lá quem como Richard Foreman (o meu grande ídolo!) no espaçozinho dele atrás da St Mark's Church (para 50 pessoas)!!!! Era um FRISSON!!!!

A crítica no Brasil serve como referência para você? Afinal, os críticos brasileiros mal reverberam fora do eixo Rio-SP... Há crítica para teatro experimental no Brasil?

Sim, tem críticos, como o Macksen Luiz que eu respeito muito. Tem o Dirceu Alves Jr, de quem eu gosto muito. Claro que, através dos tempos tivemos o Guzik e outros como o Sábato Magaldi (que não gostava muito de mim não..., mas eu admirava muito a organização acadêmica dele das obras do Nelson Rodrigues...) e tem, sobretudo, o mestre dos mestres: Jacó Guinsburg. Esse sim, é um mestre.

Em tempos de internet e de blogs, a crítica convencional (em colunas e em revistas especializadas) ainda tem poder de fechar e abrir espetáculos?

Essa era já foi. Isso quem fazia era o NY Times. Mas nem ele e nem o idiota do Trump fecham mais nada. Nem mesmo a boca (infelizmente) (rs).

Ao mesmo tempo que sua obra é objeto do interesse de jornalistas, você mesmo poderia ser considerado um jornalista reconhecido, pois fazia charges para o New York Times, manteve por anos uma coluna na Folha de São Paulo...

Começou no O Globo em 1994. Depois, a Folha (em todos os cadernos, sobretudo o MAIS), e fui para o JB, até que eventualmente colaboro com o Guardian. No NYTimes fui ilustrador da página de opinião política por cinco malditos anos. 
Você se vê como jornalista, como crítico? Ao mesmo tempo, sua relação com a imprensa parece ser de amor e tensão, pois recheada de escândalos, críticas duras, silêncios, incompreensões... Você certamente demonstra estar sempre muito atento ao que a imprensa fala sobre você. Sua relação com a imprensa é tempestuosa? Como é isso?

Tenho vários livros de crônicas pois eu colaborei (e colaboro ainda) com outros jornais (como Estado de SP) e o Globo (morte da Ruth Escobar, Tônia Carrero, Carta Aberta a François Hollande (tradução do Guardian) ... Esses livros são: Encenador de Si Mesmo e Nada Prova Nada... Sim, o Philip diz que eu tenho uma relação tempestuosa com a imprensa. Mas como eu não teria?

Beckett dizia algo como "Fracasse de novo, fracasse melhor!", o que se tornou uma espécie de mantra do experimentalismo e para o teatro de enfrentamento. No início do seu livro você se declara acostumado com a humilhação em público, por meio de críticas e escândalos. $O$ que há de fracasso profissional/pessoal ou de incompreensão nesses episódios?

Nunca fazemos aquilo que queremos fazer, querido. Isso, em si, é um fracasso. Somos um JOGO de interpretação dos outros. E isso é interessante e - ao mesmo tempo - um terror. O fracasso se dá nesse nível porque não nos reconhecemos mais. Viramos um jogo. Viramos o "outro": tem algo que escrevi sobre isso. Está em inglês mas vou citar aqui: "Self censorship exists. Whether it's imposed by external forces or internal demons, it's always there. 'the artist' is always 'someone else' as Saul Steinberg put it. And this 'someone else' (obviously a Freudian analogy), is a repressive self. This someone is NEVER there to help us 'enlarge the stage, the canvas, the road. This is a mean self and this is - perhaps - the self WE, 'the artist' hold true to be the eye of the audience: our greatest fear and most adored enemy ${ }^{4 \prime}$.

Como é, pessoal e profissionalmente, lidar no dia-a-dia com essas instâncias e de onde você sempre acha forças e inspiração para recomeçar? Afinal, você é um artista que costuma se entregar de corpo e alma ao que faz e vivemos em uma sociedade que cada vez contempla menos a orientação do indivíduo para suportar a crítica, o fracasso e a humilhação.

É como viver dentro de um açougue. Um horror. As vezes as PIORES crises depressivas vêm disso: de ler essa mediocridade. $\mathrm{E}$, ao mesmo tempo, esse terrível vicio não nos deixa de lado né?

O Facebook, antes dessa onda de ódio e apostasias, era um território no qual a vida de todos parecia maravilhosa e perfeita. Em universidades como Yale, estudantes ultramimados exigem "espaços seguros" para poderem estar sem receber críticas. É possível continuar-se humano num plano livre de críticas ou num mundo perfeitamente higienizado, tranquilo e seguro?

Me parece a coisa mais INsegura do mundo.

4 Autocensura existe. Seja imposto por forças externas ou por demônios internos, está sempre lá. "O artista" é sempre "outra pessoa" como Saul Steinberg disse. E essa "outra pessoa" (obviamente uma analogia freudiana) é um eu repressivo. Este alguém NUNCA está lá para nos ajudar a "ampliar o palco, a tela, a estrada. Este é um eu mesquinho e este é - talvez - o eu NÓS, "o artista" é verdadeiro para ser o olho da audiência: nosso maior medo e mais adorado inimigo". 
Um Circo de Rins e Fígados foi seu último grande sucesso (antes de Dilúvio)? O que deu tão certo na peça? Já, o que deu errado, por exemplo, em Entredentes?

Sim, dizem que é isso. Eu ainda colocaria no meio o Terra em Transito com a Fabiana. Adoro aquela peça, logo depois do Circo em 2006 e, aqui em NY, 2007. E, de certa forma, Queen Liar, 2008. Foram, na minha opinião, boas. Entredentes... não sei. Acho que super-escrevi. Over-writing. Exagerei e não dei respiros. Praticamente não houve encenação. Só duas pessoas falando sem parar. Sem parar.

Seu teatro também é caracterizado por uma estética muito própria. Iluminação contrastada, noir, cenários apocalípticos, distópicos, enfumaçados, pós-industriais, pós-punks - dá a impressão de que o Einstürzende Neubauten vai entrar em cena e começar a tocar a qualquer momento.

Há há há..!

Como você concebe e processa esse design? Quais são as suas referências conceituais aqui? Quem foram seus principais colaboradores na definição dessa linguagem? Como foi a parceria com Daniela, com seu senso apurado de iluminação e cenário?

Não sei te dizer. Olhe os meus desenhos desde que tenho 12 anos e me diz se existe realmente "parceria" ali (rs)?

Também no início do livro, você faz referência a teorias de conspiração e a sensações de paranoia. Você se sente paranoico às vezes? Acha que o mundo está se tornando mais paranoico? Como essa sensação chega às suas peças e seus personagens?

Sou um BOM paranoico. Existem os ruins. Eu sou um razoavelmente BOM paranoico.

Você faz em seu livro como que uma profissão de fé da busca incansável e sincera pelo significado, de tudo. Ao mesmo tempo, você zomba (nietzscheanamente, duchampianamente...?) do significado das coisas.

Você esta equacionando Nietzsche com Duchamp. Cuidado (rs). Os patrulheiros vão correr atrás de você - e mesmo Thomas Cromwell irá! Mas, perseguir os significados é o trabalho do artista, não? Ou do curioso cético em geral, não é? Eu sou autodidata (mentira, sou um "orientado" na vida, por lindos mestres como Ivan Serpa, Hélio, Ziraldo, Saul Steinberg, Ronald Heyman - meu tutor no British Museum - e assim por diante). Tenho esses "ídolos" fictícios e reais nos quais baseio a minha vida e sou OBCECADO por história distante e FATOS da hora, REAL TIME NEWS, o que está acontecendo agora, seja onde for, seja a bomba que explodiu agora em Kabul, seja a travessia dos Mexicanos de Tijuana... Sou devoto contra Trump, a direta, os fascistas, etc., e ... tento interpretar a Constituição Americana e os Founding Fathers assim como tento interpretar Finnegan's Wake....Coisas assim. Uma miscelânea que acaba virando o meu discurso - sempre caótico - no palco. Mas acho que é como REALMENTE pensamos. Nós, os seres humanos (e os cães!). 
Às vezes, você tem a extraordinária capacidade de zombar de si próprio, de não se levar a sério, sem propor-se exatamente como um humorista. Zombar do significado é uma estratégica para desconstruir permanentemente a verdade estabelecida? Para duvidar de tudo? Vive-se assim num estado de crítica permanente em relação ao entorno? É um círculo vicioso?

Não adianta explicar muito. É zombar mesmo. Zombar é zombar e pronto. Olha o RIDICULO das coisas. Olha o meu cabelo. Olha como tento ser um eterno jovem. Olha a minha geração de roqueiros! Será que não entendemos que estamos velhos? O Mick Jagger rebola SUPER BEM, mas olha os outros com a barriga caindo para fora e TODOS de cabelos tingidos. É patético!!! Pior que fuga de Bach (digo, mais previsível).

Como funciona a combinação entre drama, tragédia, provocação e humor nas suas peças e textos? Alguns de seus maiores sucessos, são, justamente, muito engraçados, ainda que poderosamente dramáticos e provocativos.

Você é muito engraçado. A primeira parte da sua pergunta é uma indagação e a segunda parte é a própria resposta (rs).

[Risos]. Desde as criações mais simples, às mais sofisticadas. Por exemplo: das melhores coisas que vi nessa época marcada por polarizações odientas, foi um post seu no Instagram, de agosto de 2016, sobre o "Fora Trump, fora Dilma, fora Temer, Fora Putin..."

"E os Filhos da Putin..."

... isso! No qual você aparece agachado, de quatro, no meio de um varal de roupas com um cocar de penas, representando uma bicha numa "floresta suíça". É engraçado e genial, porque, de fato, o "fora" é um lugar que não existe e se não quisermos aprender a conviver uns com os outros, vamos acabar refundando campos de concentração (os abomináveis campos de refugiados já existem aos montes no mundo).

(3)

Um Circo de Rins e Fígados, pareceu-me incrivelmente engraçado, mas notei que muitas pessoas na plateia emitiam um riso meio nervoso, quando riam.

E em Eletra ComCreta não? E Flash and Crash Day, não? Em todas as peças o riso é nervoso Gunter. Temo que as pessoas SÃO nervosas (rs).

[Risos]. Num episódio recente, no lançamento do seu penúltimo livro, na Livraria Travessa, no Rio de Janeiro, o pessoal do Pânico (que faz um humorismo de enfrentamento, parecido, de certo modo, com o seu teatro experimental e de enfrentamento) foi te entrevistar com uma modelaça, gostosa, num justíssimo vestido azul, mas intelectualmente limitada...

Há, há, eu nunca a ouvi descrita assim! 
... sim! (O que por si só já era uma paródia de desconstrução do papel do entrevistador), chamada Nicole Bahls, acompanhada de uma engraçadíssima drag Micome Balls e do não menos divertido personagem Tucano Huck. Você acabou interagindo de forma inesperada com o trio, tentando pôr a mão sob os vestidos para ver quem era "homem" e "mulher". Foi cômico. Ficou claro que a turma do Pânico como que te entregou um leque de cartas, você o tomou, o re-embaralhou e o devolveu a eles. Isto é, estavam todos no mesmo registro. No entanto, muitas pessoas, sobretudo jovens e universitários, inclusive, não compreenderam o contexto e o criticaram por assédio, exibicionismo, machismo, etc...

Acho que as redes sociais, sobretudo elas, pularam em cima daquilo e transformaram num evento "Homem ataca mulher" - assim como o Harvey Weinstein, etc. Mas foi tudo NA FRENTE DAS CAMERAS. Caramba! As feministas pegaram para elas e virou: ESTUPRO!!! É uma loucura o jogo político!!! Você pode transformar qualquer palavra em qualquer outra, qualquer imagem em qualquer outra: Goebbles, em qualquer outro. Viva Barthes! E Viva Sontag!

Você acha que as pessoas se tornaram literais? Como fazer humor se metáforas e metalinguagem deixam de ser compreendidas?

Temos que ENFIAR (voltar a enfiar) SUTILEZA goela adentro. Como sutileza e enfiar não se complementam, esse projeto é, em si, um fracasso (rs).

Você parece ser um "ser teatral", alguém que muito cedo se apaixonou pelo teatro e vive inteiramente para o teatro. Vêm daí excentricidades que eventualmente desconcertam as pessoas? Há para você uma fronteira clara, objetiva, entre palco e vida privada ou cotidiana? Qual é? Você é um encenador de si mesmo?

Eu só entendo a vida assim, cara. Não entendo a vida fora do palco. Juro que não. Acho TUDO isso uma ENORME ENCENAÇAO. TUDO!!!!

No passado (penso no Brasil, por exemplo, do período da ditadura militar), artistas e autores diversos faziam jogos de palavras e trocadilhos para driblar a censura e criticar o status quo.

E, assim que a ditadura acabou, "afasta de mim esse cale-se" virou...

As pessoas, bem ou mal, entendiam. De Chico Buarque a Rita Lee, passando pelos pioneiríssimos Dzi Croquetes, o trocaditho, a paródia e a metáfora eram ferramentas de trabalho. Hoje, as instituições são democráticas (pelo menos na forma e na aparência), mas o politicamente correto agressivo e o seu contraponto extremo, o fundamentalismo direitista-religioso, pretendem policiar cada palavra proferida. Feministas histéricas consideraram recentemente Chico Buarque machista, assim como já disseram no passado que os Rolling Stones eram misóginos. Na contraface, muçulmanos fanatizados ofendem-se com charges do Profeta e neopentecostais brasileiros horrorizam-se com representações do nu em obras de Adriana Varejão, Fernando Baril, Volpi, Portinari e Lygia Clarck expostas em museus. Como é para o artista enfrentar a censura dos dias atuais?

Nossa! Que pergunta. Tive que pegar três cafés! Acho que as minhas respostas 
anteriores estão ...olha...já falei sobre isso. Uma certa restrição é importante para o artista. É ruim dizer isso? Paciência. Que BERREM!!! Mas a liberdade total pode dar em merda.

Como é ter tido a própria bunda discutida no Supremo Tribunal Federal há cerca de $\mathbf{2 0}$ anos e agora montar uma peça num Brasil onde uma performance com um homem nu em um museu gera catadupas de reações indignadas contra suposta pornografia, pedofilia, etc... Nada mudou, há retrocesso ou estamos replicando o que os Estados Unidos passaram nos anos $1980 \mathrm{com}$ exposições como as de Mapplethorpe?

Até hoje eu não sei o que foi aquilo. Claro que teve muita coisa de "evangelismo' da Rosinha e do Garotinho naquilo, mas teve algo mais que ninguém sabe explicar. Como isso tudo foi parar na capa do NYTimes e do Guardian e da imprensa TODA do mundo, isso eu não sei. "The Case of the Mooning of the Opera in Rio". Que loucura que são as coisas. Nunca vejo as coisas somente como um retrocesso. Também não adianta comparar com as fotos do Robert Mapplethorpe ou de quem quer que seja porque aquilo é uma foto e será visto numa galeria exclusiva e... enfim, não há como comparar. Antes do Mapplethorpe existiu o Dadaísmo e - digamos a Contracultura - de onde eu venho ou a geração dos filmes do Warhol/Paul Morrisey ou Kenneth Anger onde tudo era picada de heroína ou picada de chupada ou John Waters mas, e daí? O dia de amanhã? Teremos sempre um Alexandre Frota para enfrentar não? (Rs)

Dentre os muitos aspectos admiráveis em Bowie está o fato de que ele sempre fez crítica social e política, mas jamais reduziu a grandeza de sua arte a uma bandeira. 0 movimento gay chegou a criticá-lo (o homem que criou Ziggy Stardust!!!) pela filmagem de Marry Christmas, Mr. Lawrence, por falta de engajamento em favor da causa. Por outro lado, há artistas que assumem de tal modo uma determinada bandeira, que acabam confundindo-a com a sua arte. Você é filiado no Partido Democrata, fez campanha em favor de Obama, milita constantemente contra Trump, mas a sua arte e a sua persona não parecem de modo algum reduzidas a essas ou outras bandeiras ou nelas engajadas de modo exclusivista. Como encontrar o ponto de equilíbrio?

Acho que essa é uma era em que as pessoas estão se olhando no espelho e se perguntando - assim como na era que J P Sartre "inaugurou" - "QUEM SOU EU?". E, de uma forma NÃO LINEAR (e isso é muito importante - diferente do Cartesianismo de Sartre e de Corbusier e de Levi-Strauss e dessa turma), enfim, de uma forma assimétrica, estão se vendo como um quadro de Paul Klee, numa perspectiva confusa, tentando se ENXERGAR. E nessa tentativa, TUDO é necessário. Bandeiras são importantes, SIM. Alguns gêneros e falta deles, essa enorme discussão sobre a falta de gênero (inexistência dele) trans., etc, é de SUMA IMPORTANCIA... AS PESSOAS ESTAO SE REINVENTANDO. Assim começa. Começa pelo sexo. E depois vai para a sala de estar. Depois para a cozinha. Depois para as utilidades. E depois se espalha. Uma década depois, ninguém mais sabe o que aconteceu, fora os behavior-freaks. Sim, fiz campanha para o Obama, mas faria para qualquer campanha que LIBERA o SER HUMANO DE SUA SOMBRA FASCISTA!!!! 
Você diz no início de seu livro que a sua arte, o teatro experimental, está morta. A afirmação é coerente com o seu manifesto de abandono dos palcos, de julho de 2009.

Mantenho aquilo. Nada mudou.

No entanto, em 2011 você já estava envolvido com a montagem de uma peça em Londres. E, em 2017, montou Dilúvio em São Paulo, com notável sucesso. Há sobrevida para o teatro experimental? Ou há chance para um renascimento? Qual o contexto que teria matado o teatro experimental: um mundo cheio de certezas, gentrificado, que projeta um idílio edulcorado, no qual a crítica ácida e constante não é mais bem-vinda?

Foi uma bobagem ter voltado.

Você diz no livro que o teatro perdeu a capacidade de atingir, convencer e inspirar as pessoas. Apenas o teatro experimental ou todo ele? Por que?

Porque não há mais paciência, não há mais dinheiro e não há mais attention spam. Mas, sobretudo...não existem mais INVENTORES DO TEATRO. TUDO TEM UM FIM.

A crítica Camille Paglia tem dito algo semelhante com respeito à arte contemporânea, registrando a dificuldade cada vez maior de se identificar um "great artist" capaz de mobilizar e inspirar as pessoas em larga escala. Ela parece abrir uma exceção para alguns episódios de Guerras nas Estrelas, para a arte em desenho animado e em videogames. Você concorda com isso?

Sim, totalmente.

Escrever, pintar, encenar podem ser atividades libertadoras? Como? Ou podem se converter em processos de aprisionamento?

Eu, pessoalmente, sou escravo disso tudo.

Você tem um tipo de assinatura Hitchcockiana nas suas peças - uma caminhadinha no palco, uma interação inesperada com a plateia, a sua voz saindo da coxia e suas frases sendo repetidas no palco pelos atores (como em The Flash and The Crash Days, no Theatro São Pedro, quando lá pelas tantas você fez Fernanda Montenegro dizer "Pessoas tossindo... não estão preparadas para ir ao teatro..."), o instrumento de percussão tocado no canto do palco (como em MatoGrosso).... Como é ser esse diretor participativo, que também aparece no palco, produz, fala com a plateia? Chega a ser uma atuação?

Não passa de uma brincadeira. Geralmente são os atores que insistem em que eu entre. Geralmente eu estou na coxia durante o espetáculo, fazendo a manobra da direção técnica toda lá. Então, as vezes é melhor entrar e curar o meu ego/ícone mesmo (rs).

Há alguns anos você vem escrevendo sistematicamente na Internet. Você teve mais de um blog.

O mesmo blog, hospedado em lugares diferentes: UOL, IG e agora Wordpress. O mesmo conteúdo. 
No IG, você fazia sucesso, mas resolveu encerrar o projeto e começar outro. Eles encerraram o contrato. Foi o PT, precisamente.

O que deu certo e o que deu errado nas experiências que você vivenciou na Internet? Do que você mais gostou, do que você menos gosta, nos blogs, nas redes sociais (nas quais você também é muito ativo)?

Eu ODEIO tudo isso, mas é um vício, como todos os vícios. Se eu pudesse, estaria fazendo tricô com o Mick Jagger, mas ele não quer. Então, eu também não quero.

A Internet surgiu com uma promessa de quebra de barreiras e de fronteiras. Você vive e/ou trabalha em cidades e países diferentes - Londres, Nova lorque, Suíça, Rio de Janeiro, São Paulo... - você acha que as fronteiras (sobretudo as culturais e simbólicas) estão mais ou menos enfatizadas? A Internet na sua opinião tem contribuído mais para incentivar o cosmopolitismo ou o regionalismo e o provincianismo?

Todo lugar é....... (*essa pergunta não tem resposta. Ou melhor, a resposta é do tamanho de uma enciclopédia).

Me ocorrem pouquíssimos casos de grandes artistas que lograram fazer da própria morte uma obra de arte. Penso em David Bowie, com Lazarus; Mapplethorpe, naquele autorretrato com uma caveira na ponta da bengala; e na atuação de Julian Beck na peça de Beckett que você dirigiu. Como foi a experiência de dirigir essa peça, especialmente se consideramos o quanto você fica emocionalmente impactado com o passamento de amigos próximos?

Esse "detachment" é foda. Difícil!!! Os dois conseguiram. Eu sou uma vítima mesmo com um simples resfriado. Imagina! Eles tocaram a arte já se sabendo terminais. Eu conversava o dia inteiro com o Julian sobre isso. Raramente eu conseguia uma resposta adequada. Ele mesmo não entendia.

Como um hipocondríaco enfrenta a própria morte?

É uma maneira rápida de sanar todos os males e de chegar "lá" mais rapidamente.

Dentre os motivos pelos quais o suicídio é difícil de tratar pela psicanálise é que poucos suicidas voltam para contar como foi. Você já disse que não se orgulha e nem se arrepende da tentativa de suicídio nos Alpes em 2015, mas algo mudou em você?

Essencialmente não. Luto contra a depressão todos os dias. Todos os dias.

Como foi a experiência da montagem de Dilúvio em São Paulo? Tudo o que li a respeito foi muito positivo e elogioso. As redes sociais enlouqueceram com a peça...

Esses elogios pouco importam. A dinâmica interna da companhia é o que importa. E o fato de que aquilo parou (estacionou) lá em Nov-Dez do ano passado é desesperador. Tanto trabalho para que? Não sei. Explica porque o teatro é um desperdício. 
Você disse que não há previsão de itinerar Dilúvio - com temporadas no Rio, etc. Ainda é assim? O que você programa para a peça?

Acabou Gunter. Não programo mais nada.

Você está trabalhando em um novo projeto no momento?

Levar a vida mais um dia. Só mais um. LOVE. Gerald Thomas.

Recebido em: $13 / 05 / 2018$

Aprovado em: 15/05/2018 